\title{
PROCEDIMIENTOS MÉTRICOS EN LA LÍRICA UNAMUNIANA
}

\author{
Manuel Romero Luque
}

Resumen: La prolífica figura de don Miguel de Unamuno es, sin duda, una de las cimas literarias del siglo xx. No obstante, su labor como poeta lírico ha sido con frecuencia, hasta tiempo bien reciente, echada en olvido. Este trabajo pretende exponer cómo la poética del rector de Salamanca demuestra, desde el primero de sus libros hasta su póstumo Cancionero, un notable conocimiento de la tradición literaria y sus procedimientos métricos, así como su capacidad para innovar dentro del panorama literario de su tiempo, en el que consolidó una obra al margen de los estereotipos vigentes. Su lírica queda caracterizada por la variedad en el cultivo de metros, en la que se aprecia una evolución desde el ritmo endecasilábico al octosilábico; la abundancia de formas estróficas que utiliza, aunque el soneto sea la figura central, y la valoración cambiante que suscita en el poeta el uso de la rima.

Palabras clave: Poesía lírica, Unamuno, métrica, ritmo, soneto, rima

Abstract: Without a doubt, the prolific figure of Miguel de Unamuno constitutes one of the pinnacles of twentieth-century literature. However, his output as a lyric poet has, until of late, been frequently neglected. This study aims to shed light upon how, from the first of his books until his posthumous Cancionero, the Principal of Salamanca University reveals his remarkable knowledge of literary tradition and its metrical procedures, together with his capacity for innovation within the panorama of the literature of his time, as part of which he built up a creative corpus beyond the confines of the stereotypes in vogue. His lyric poetry is characterized by the diversity of its crop of metrical types, within which a rhythmic evolution, from hendecasyllables to octosyllables, is observable; by the wide range of stanzaic forms undertaken, 
although it is the sonnet which is the main form employed; and by the ever-changing range arising out of the poet's use of rhyme.

Keywords: Lyric poetry, Unamuno, meter, rhythm, sonnet, rhyme 
7 odo gran autor va haciendo su obra al paso que hace su lenguaje. Si ese bien común que es la lengua se modula $\mathrm{y}$ adquiere sus propios matices en cada voz, en la de los poetas esto se acusa de manera especial y el ejercicio de la métrica, el uso que hace del verso y sus recursos, es un valor imprescindible para construir su propio universo poético. Así, igual que la lengua tiene unos procedimientos básicos a los que deben recurrir sus hablantes para comunicarse, los poetas reciben de la tradición literaria una serie de principios que potencian o reelaboran conscientemente para el desarrollo de su labor creadora. Sus variaciones, sus reincidencias, sus observaciones sobre ese acervo común declaran también cuáles son sus intenciones de renovación o asentamiento dentro de una tradición determinada.

La poesía de Unamuno es un lugar privilegiado para el estudio de muchos aspectos relativos a la lírica que desde comienzos del siglo xx y hasta el final de su primer tercio tienen lugar en esa edad de plata de la literatura española. Su indudable personalidad que marcó su huella en la novela, el ensayo y el teatro de su tiempo luchando contra esto y aquello -expresión que adoptaría como título bien expresivo de uno de sus libros- no podía estar ausente de su quehacer como poeta, máxime cuando él, reiteradamente, insistía en que ésta debía ser la consideración por la que debía quedar en el panorama literario por encima del resto de sus ocupaciones.

Sin embargo, esa posición incómoda que ofrece, para algunos investigadores, quienes se sitúan atrevidamente en un lugar de encrucijada y se resisten a someterse a rígidos modelos clasificatorios ha dejado al margen, hasta hace escaso tiempo, la producción en verso del autor bilbaíno que, no obstante, se yergue altiva entre el genio de Rubén, la gracia del verso de Manuel Machado o la solemnidad de su hermano Antonio, el misticismo lírico de 
Juan Ramón y la floración espléndida que trajo el 27. Ese abrirse hueco y quedarse ahí plantado como una palmera -símbolo tan querido para Unamuno- en medio de todos, en tierra de nadie -en su propia tierra, abonada con sus versos-, azotado por todos los vientos, sin que nadie pudiera hacerlo suyo por completo, es el sello más característico de su propia poética; una poética en la que cobra especial relieve ese dominio particular que muestra de los recursos métricos y lo diferencia de los demás poetas del momento.

La primera nota definitoria de su poesía viene dada por su condición de poeta tardío, pues, el afamado rector salmantino cumple cuarenta y tres años cuando publica su primer libro de versos, Poesías (1907), ${ }^{1}$ pero precisamente por ello, como reconocieron de primera mano Juan Ramón Jiménez o el propio Darío, su voz carece de los titubeos iniciales que suelen detectarse en un principiante. Así, la obra, aunque transparenta ecos de indudable filiación decimonónica, es suficientemente innovadora para el panorama de su tiempo y deja ya establecidos los principales motivos de preocupación de la poética unamuniana, ${ }^{2}$ a la vez que demuestra un buen dominio de los procedimientos técnicos y un amplio repertorio de formas métricas.

En Poesías aparecen desde cuartetas asonantadas, que alternan versos octosílabos y hexasílabos, hasta romances que muestran una variada gama de metros (octosilábicos, endechas o heroicos) y décimas (según el modelo: $8 \mathrm{a}, 8 \mathrm{~b}, 8 \mathrm{a}, 5 \mathrm{~b}, 8 \mathrm{c}$ ', $8 \mathrm{~d}$, $8 \mathrm{e}, 8 \mathrm{~d}, 5 \mathrm{e}, 8 \mathrm{c}$ '). A veces, crea estrofas de cuatro versos en las que los tres primeros son dodecasílabos y el último octosílabo, con

${ }^{1}$ Esto no quiere indicar que Unamuno no hubiera escrito antes poema alguno, pues, como ha señalado el profesor Carlos Serrano, ya en 1893 se publicaron en el suplemento literario del diario El Nervión y más adelante, en 1899, también habían salido a la luz algunas composiciones que aparecieron en La Revista Contemporánea y la Revista Nueva, amén de mostrar su intención en carta personal de publicar en breve un libro de poemas que bien hubiera podido editarse en el año 1900. Cfr. Serrano, Carlos: "Prehistoria poética de Miguel de Unamuno" en José Ángel Ascunce Arrieta (ed.), La poesía de Miguel de Unamuno. San Sebastián: Facultad de Filosofía y Letras de la Universidad de Deusto, 1987, pp. 17-23 y García Blanco, Manuel: "Introducción” a Miguel de Unamuno, Obras Completas, t. VI. Madrid: Escelicer, 1966, pp.11-12.

${ }^{2}$ La primera parte del libro es un conjunto de seis poemas que, bajo el título general de "Introducción", sirve de manifiesto poético sobre las intenciones generales del autor. Cfr. Unamuno, Miguel de: Obras Completas, t. VI. cit., pp.167-175. 
asonancia en los pares, y hay también poemas en los que alterna decasílabos y hexasílabos con rima consonante entre sí; además de diversos tipos de sextillas agudas (8a, 4a, 8b', 8a, 4a, 8b') (12A, 12A, 6b', 12C, 12C, 6b').

Prefiere, sin embargo, las composiciones de ritmo endecasilábico, entre las que pueden encontrarse: silvas diversas (sin rima, con rima consonante o arromanzadas), estrofas sáfico-adónicas (con rima o sin ella), endecasílabos blancos o agrupados en serventesios y variadas composiciones polimétricas; aunque llama la atención el escaso uso que hace del alejandrino a pesar de que éste es el verso de moda y que sólo aparece en ocasiones combinándose con el heptasílabo en estrofas de seis versos (14A, 14B, 7c, 14A, 14B, 7c); igualmente, el soneto, estrofa central de su poética, aparece desde su primer libro y, entre los que allí aparecen, resulta especialmente relevante con respecto al tema que ahora nos ocupa el titulado "A la rima", donde muestra su rechazo a este elemento métrico, aunque después -como veremosvariará esta consideración inicial. Este primer Unamuno considera la rima como un pesado yugo que lastra la libertad de la poesía, aunque, de momento sea menester soportarla: ${ }^{3}$

Macizas ruedas en pesado carro, al eje fijas, rechinante rima, ¡con qué trabajo llegas a la cima si al piso se te pone algún guijarro!

Al tosco buey, que no al corcel bizarro, el peso bruto de tu lanza oprima pues al buey sólo tu chirrido anima cuando en piedras te atascas o en el barro.

Mas en tanto no quede, sin maraña, la selva, como el mar, toda camino, tira, noble corcel, de ese armatoste,

pues más te vale la coyunda extraña, no siendo aún la libertad tu sino, que estarte en el establo atado a un poste.

\footnotetext{
$\overline{{ }^{3} \mathrm{Ibi}}$. p. 314. Nótese la dura sonoridad que ha forzado el poeta en la selección de las rimas del soneto para hacer ver el peso que sobre el poema recae con ese recurso que, por ahora, detesta. El poema está fechado en 1900 y, según García Blanco, fue publicado en 1901 en El Imparcial (Ibid.).
} 
Cuatro años más tarde, en 1911, Unamuno publica su segundo libro de versos que llevará por título Rosario de sonetos líricos. Como el título indica la obra es un conjunto de sonetos -128 en total- que aparecen ordenados cronológicamente 4 y que fueron compuestos en un breve periodo de apenas cinco meses, desde septiembre de 1910 hasta febrero de 1911, ofreciendo con ello un testimonio de su capacidad para adaptarse a la reina de las estrofas. Esta febril actividad poética que mantuvo produce un doble efecto que resulta extensivo a otras partes de su producción: de un lado, que la obra poética de Unamuno pueda leerse casi como un diario ${ }^{5} \mathrm{y}$, por otro, que esa intensiva dedicación al cultivo de una estrofa determinada, en este caso el soneto, contribuye al dominio que alcanzó de esa forma métrica y que lo acompañará ya siempre hasta el final de sus días.

En 1911, su posición sobre el valor de la rima como procedimiento métrico ha variado notablemente. Si en el poema anteriormente reproducido, ${ }^{6}$ la rima es un freno, ahora el poeta viene a contradecirse de una manera evidente. Este cambio de postura es de gran interés porque refleja no sólo un grado de evolución, sino esa tarea constante que realizó a lo largo de su vida de repensar constantemente sus aseveraciones, acendrando su labor como poeta. Esa rima, antes denostada, alcanza ahora con el ejercicio continuado del soneto un nuevo valor. Se convierte en un elemento fundamental que proyecta la fuerza creadora del autor y lo lanza a la búsqueda de nuevas asociaciones que redundan en beneficio del resultado final. Así dirá:

" En el "Epílogo" que escribe Unamuno a esta obra nos declara: "No he querido ordenar los precedentes sonetos, fruto de cinco meses, por materias, prefiriendo presentarlos en el orden cronológico de su producción, que es además, por ser el genético, el más íntimo" (Ibid., p. 414).

${ }^{5}$ Así, el libro aparece dividido en secciones de acuerdo con el lugar en el que fueron surgiendo y establecen un itinerario geográfico real, que parte de Bilbao y sigue por Salamanca, Asturias y León para concluir de nuevo en la ciudad salmantina.

${ }^{6}$ El poema que ya en Poesías aparece fechado en 1900 fue publicado, según García Blanco, en 1901 en El Imparcial (OC, VI, 314). Es decir es un testimonio de enorme importancia que recoge su posición sobre la rima en un trayecto que va desde sus balbuceos como poeta hasta 1911 y que, precisamente, porque recoge aún su pensamiento en 1907 sobre este recurso métrico pudo ser incluido en su poemario inaugural. 
A lo que me ayuda la rima, a la que tanto he desdeñado, pero con la que empiezo a congraciarme. Porque la rima [...] es una fuente de asociación de ideas y una fuente que no depende de nuestra voluntad. Es el lenguaje que se nos impone; es algo social; algo objetivo. Para colocar una consonante, tenemos que dar al pensamiento un giro nuevo. ${ }^{7}$

El modelo que Unamuno va a seguir en sus sonetos es el clásico: versos endecasílabos distribuidos en dos cuartetos de rima abrazada y dos tercetos que, dentro de la libertad que la estrofa permite, suelen adoptar el tipo CDC DCD. ${ }^{8}$ No obstante, don Miguel también experimenta algunas variaciones. Las más relevantes en cuanto a los cuartetos pasan por cambiar el orden de la rima en los cuartetos a la manera ABBA BAAB (soneto LXXXI); sustituir los cuartetos por serventesios de igual rima (LXXIX, LXXXVII) o distinta (LXVII, LXX, LXXX); o bien concluir el soneto con un pareado (CDC DEE), a la manera de la poesía inglesa, aunque nuestro oído no se haya acostumbrado generalmente a dichos finales. Así ocurre en los sonetos XXXIX o XLVIII. El primero de los citados, "La oración del ateo", termina:

¡Qué grande eres, mi Dios! Eres tan grande que no eres sino Idea; es muy angosta la realidad por mucho que se expande para abarcarte. Sufro yo a tu costa, Dios no existente, pues si Tú existieras existiría yo también de veras. ${ }^{9}$

Y en esa experimentación con la rima, una vez descubierta sus múltiples posibilidades expresivas, llega a recurrir a las rimas esdrújulas (LXIX y LXXVII), poco frecuentes en nuestra lengua, y que provoca un efecto acusado de contraste. Así, en "Tragicomedia", juega con las rimas en palabras llanas de los cuartetos con las esdrújulas que culminan los versos de los tercetos, causando ese efecto que anuncia el título del poema: ${ }^{10}$

\footnotetext{
${ }^{7}$ Unamuno, Miguel de: Obras Completas, t. VIII. cit., p. 285.

${ }^{8}$ Dentro de ese modelo clásico le sigue en frecuencia de uso para los tercetos el esquema CDE CDE.

${ }^{9}$ Unamuno, Miguel de: Obras Completas, t. VI. cit., p. 358.

${ }^{10}$ Ibid., p. 380.
} 
Pues lo único que el hombre cumple en serio es nacer; luego en derredor le asedia la farsa, y como Dios no lo remedia ni sirve del pesar el cruel cauterio da en actor. $Y$ en este ministerio cobra de la tal vida triste acedia y la muerte es escena de comedia aunque prólogo sea del misterio.

Los pasos del teatro siendo míticos henchidos suelen ir de efectos mágicos y por tristes razones económicas

los dos momentos de la vida críticos, los nacimientos casi siempre trágicos y son las muertes casi siempre cómicas.

De acuerdo con ese carácter clásico de la estrofa, Unamuno va emplear el metro endecasílabo en estos sonetos, salvo en seis ocasiones en que prefiere hacer uso del alejandrino. Se trata de los sonetos XLIX, LVI, LXIV, LXV, LXXXVII y CXXIII.

En carta a Juan Arzadun, fechada de 28 de octubre de 1910 y recogida por García Blanco, el poeta dirá: "Y hago sonetos. Pero sonetos clásicos, de catorce endecasílabos y con todas las de la ley. Llevo ya hechos noventa y cinco. Cuando tenga unos más publicaré un tomo de ciento y pico de sonetos". ${ }^{11}$ Esta declaración es especialmente interesante porque en esa misma fecha Unamuno ya había escrito cinco de los seis sonetos más arriba mencionados, entre el 30 de septiembre y el 27 de octubre. Ese olvido resulta, por tanto, curioso y, aunque el número de estos sonetos sea escaso, debe merecer nuestra atención.

Si el endecasílabo es el metro clásico por excelencia en el cultivo del soneto, por aquellos años, con la llegada del Modernismo, el alejandrino va a entrar también en liza para ocupar un primer plano entre los poetas del momento y, por consiguiente, su uso aparece frecuentemente extendido en el cultivo de dicha estrofa. En este sentido, los casos de Manuel Machado y Juan Ramón Jiménez resultan paradigmáticos. Así, Dámaso Alonso es un esclarecedor trabajo sobre el mayor de los Machado -y en

\footnotetext{
${ }^{11}$ Unamuno, Miguel de: Obras Completas, t. VI. cit., p. 14. Esa misma fecha lleva el soneto LXXXIX del libro de lo que se deduce que seis de lo sonetos escritos hasta la fecha no fueron publicados finalmente en el Rosario de sonetos líricos.
} 
el que alude también tanto al poeta de Moguer como al catedrático salmantino para establecer concomitancias y divergencias entre ellos- dirá: "Ahora en los umbrales del siglo xx, el alejandrino no es un verso más: es un verdadero favorito, a la par del endecasílabo, y aun con ventaja sobre este metro", para añadir seguidamente: "que este alejandrino, en realidad no empalma -o escasamente- con la tradición española, sino que viene transplantado del francés, es indudable. ${ }^{12}$

Este afrancesamiento del metro que lo convierte en nuevo consistiría, a decir del mismo Dámaso Alonso, en mantener las condiciones tradicionales en cuanto su medida, pero tendiendo puentes entre ambos hemistiquios. No se trata, pues, del alejandrino medieval español, inflexible en la separación rítmica y de sentido de ambos hemistiquios. Ahora, la pausa medial característica del verso no desaparece, se suaviza. Como afirma el maestro de la crítica española: "Esto nos indica, desde ahora, que es criatura titubeante; que lo que busca es vaguedad, fluidez, imprecisión y, a la par matiz"13 y, así, en total concordancia con los principios que Verlaine dictó en su "Arte poética" tan venerado por los modernistas españoles.

La inclusión de estos sonetos alejandrinos en el libro hace que nos formulemos una pregunta: ¿serían estos poemas una especie de tanteo al que se somete Unamuno, tan enemigo por otra parte de "modernisterías", para probarse con el verso propio de su época? y, junto a ésta, otra cuestión más: ¿ese olvido que hace de ellos en la carta más arriba mencionada indicaría que no pensaba darlos a la imprenta y que sólo después, para mantener ese orden íntimo que recoge en su epílogo, decidiera publicarlos?

Otra cuestión problemática es la consideración de estos sonetos como tridecasílabos. Así lo afirman dos de los editores de sus poesías Manuel García Blanco ${ }^{14}$ y Ana Suárez Miramón ${ }^{15}$ $\mathrm{y}$, más recientemente, el profesor Domínguez Caparrós ${ }^{16}$ en un

\footnotetext{
$\overline{{ }^{12}}$ Alonso, Dámaso: "Ligereza y gravedad en la poesía de Manuel Machado" en Poetas españoles contemporáneos. Madrid: Gredos, 1969, pp. 49-95, p. 58.

${ }^{13}$ Ibid., p. 58

${ }^{14}$ Unamuno, Miguel de: Obras Completas, t. VI. cit., p. 14.

${ }^{15}$ Suárez Miramón, Ana: "Prólogo" a Poesía completa, vol.1. Madrid: Alianza, 1987, p. 254.

${ }^{16}$ Domínguez Caparrós, José: "Sonetos tridecasílabos de Unamuno" en Filología y Lingüistica. estudios ofrecidos a Antonio Quilis, vol. II. Madrid: CSIC-UNED y
} 
pormenorizado trabajo en el que analiza cada uno de estos seis sonetos.

En nuestra opinión, como ya tuvimos ocasión de exponer en un trabajo anterior, ${ }^{17}$ estos sonetos están compuestos por versos alejandrinos ${ }^{18}$ que siguen las pautas de dicho metro según lo entienden la mayor parte de los poetas de principio del siglo xx y que, como hemos indicado, consiste en atenuar un ritmo excesivamente marcado. ${ }^{19}$ Rubén Darío, los Machado y Juan Ramón, y al lado de éstos el grueso de la tropa modernista, se alinean en defensa del nuevo metro y lo ensayan decididamente. Unamuno conoce bien la obra de estos poetas principales y no sería extraño que intentara seguir el modelo, aunque tal vez no se encontrara a gusto con él.

Así pues, estos alejandrinos no dejan de ser versos compuestos de dos hemistiquios heptasílabos con una cesura medial y ante la cual rigen las mismas reglas para el cómputo silábico que ante la pausa final de verso. Se trata de potenciar, sobre todo, la tensión que se produce entre la cesura y los elementos del verso separados por ella. Y así, una palabra aguda al final del primer hemistiquio supone añadir una sílaba más según el sistema convencional español o una palabra acabada por vocal no podrá hacer sinalefa con la primera sílaba del siguiente hemistiquio. (En estos casos estaríamos hablando de lo que se ha venido denominando alejandrinos a la francesa.) $\mathrm{O}$ bien se dotará de mayor intensidad acentual al monosílabo situado antes de la pausa medial e incluso, mediante un encabalgamiento léxico, una misma palabra podrá quedar escindida entre ambos hemistiquios (supuestos que han recibido la denominación de alejandrinos ternarios). ${ }^{20}$

U. de Valladolid, 2005, pp. 1923-1938.

17 Romero Luque, Manuel: Poesía y visión poética en don Miguel de Unamuno. Sevilla: Padilla Libros, 2000, pp. 124-134.

${ }^{18}$ Sólo cabría señalar como excepciones la inclusión de dos endecasílabos en este conjunto de sonetos y un verso que exigiría traslación acentual al final del primer hemistiquio para adecuarse a las normas del alejandrino.

${ }^{19}$ Leopoldo de Luis ha subrayado al respecto cómo la atenuación de esa cesura medial contribuye a que el verso alejandrino ofrezca como resultado un ritmo más ondulante, original y grato. Cfr. Luis, Leopoldo de: "Prólogo" a Juan Ramón Jiménez, La soledad sonora. Madrid: Taurus, 1981, pp. 9-47.

${ }^{20}$ Cfr. Torre, Esteban: Métrica española comparada. Sevilla: Publicaciones de la Uni- 
Lo verdaderamente importante al respecto es resaltar, como ha señalado con justeza el profesor Esteban Torre, que:

Existe, así pues, una oposición, una tensión dialéctica, entre el modelo métrico, por una parte, $y$, por otra, el modelo de ejecución (o de recepción) y su actualización en una "lectura normal". Se trata de una oposición no excluyente, sino dialéctica; ya que la forma de la expresión rítmica, que está prefigurada en el modelo métrico, no anula sino que potencia y realza, la forma del contenido morfosintáctico y semántico. ${ }^{21}$

El profesor Domínguez Caparrós, por su parte, en el trabajo que dedica a esta cuestión, aunque señala que es posible medir como tridecasílabos los versos unamunianos, y así lo hace en su artículo, no deja de notar que el tridecasílabo difícilmente logra individualidad rítmica en estos sonetos y así, al analizar el número XLIX, señala:

El que once de estos versos estén acentuados en sexta sílaba ayuda a que la referencia rítmica al alejandrino sea la más familiar y que se interpreten como tales. Esta dificultad de identificación rítmica se confirma en el análisis de los otros sonetos. ${ }^{22}$

Sin embargo, en los tres versos de este soneto en los que no marca la sílaba sexta $\left(1^{\circ}, 9^{\circ}\right.$ y $\left.10^{\circ}\right)$ sí señala un acento secundario que recae sobre monosílabo en posición final de hemistiquio ${ }^{23}$ $\mathrm{y}$, por tanto, podrían considerarse como alejandrinos de los denominados ternarios. De este modo, lo que tendríamos aquí sería precisamente el testimonio de algunos de esos hallazgos que persiguió la poesía de principios del siglo xx y que, como señaló también Dámaso Alonso, en el trabajo más arriba citado, sería una de las mayores aportaciones a la métrica española del momento: "Creo que una de las mayores intuiciones oscuras (si vale la expresión) que han tenido nuestros modernistas es la de

versidad de Sevilla, 2000, pp. 86-90; y, más específicamente, TORRE, Esteban: "La segmentación del verso: el alejandrino como paradigma" en El ritmo del verso. Estudios sobre el cómputo silábico y la distribución acentual, a la luz de la Métrica Comparada, en el verso español moderno. Murcia: Universidad de Murcia, 1999, pp. 79-99.

${ }^{21}$ Torre, Esteban: El ritmo del verso..., cit., p. 92

${ }^{22}$ Cfr. Domínguez Caparrós, José: “Sonetos tridecasílabos...”, cit., p. 1927.

${ }^{23} \mathrm{Ibid}$. 
la utilización con fines rítmicos de los acentos secundarios". ${ }^{24}$

En caso parecido estaríamos en el número CXXIII, con ocho alejandrinos ternarios, sólo que ahora siete de ellos tienen encabalgamiento léxico entre sus hemistiquios $\left(3^{\circ}, 5^{\circ}, 6^{\circ}, 8^{\circ}, 12^{\circ}, 13^{\circ}\right.$ y $14^{\circ}$ ) y sólo uno acaba en monosílabo $\left(1^{\circ}\right)$ que por su posición final de hemistiquio cobraría ese acento secundario.

Es cierto que en otro, el LVI, hasta diez de sus versos podrían considerarse como tridecasílabos anapésticos (acentuación en $3^{\mathrm{a}}, 6^{\mathrm{a}}, 9^{\mathrm{a}}$ y $12^{\mathrm{a}}$ ), pero éste es un verso simple de estructura rítmica distinta a los cuatro versos restantes que no pueden medirse como tales, mientras que todos los versos del soneto sí admiten su consideración como versos compuestos (ocho ternarios y seis del tipo a la francesa).

En cualquier caso, lo que es cierto es que el alejandrino empleado por Unamuno, como señala el profesor Domínguez Caparrós, ${ }^{25}$ adquiere una mayor flexibilidad que en el poema de Rubén Darío que se toma como punto de referencia en su artículo. Estamos, claro es, en un tiempo de profundos cambios en la métrica y parece a punto de cumplirse ese proceso de la evolución que indica el profesor Pablo Jauralde:

La época de esplendor de los tridecasílabos -a veces llamados tricasílabos- es la del siglo XIX, pues fue objeto de análisis y ensayos no sólo de los poetas, sino sobre todo de los preceptistas. Todo ello culminó, con la renovación de los alejandrinos, a los que se sometieron los tridecasílabos durante el modernismo, y con ciertos ensayos curiosos para hacerlo funcionar como verso exento. ${ }^{26}$

En definitiva, don Miguel, al que tanto le gusta adentrarse en los entresijos de la literatura, se limita aquí a explorar las posibilidades que le ofrecía el verso alejandrino, huyendo de ese redoble molesto al oído que hubiera supuesto seguir una pauta inflexible y repetitiva. Es evidente, por otra parte, que Unamuno no se prodigó en el uso de este tipo de verso y que sólo lo utilizó en contadas ocasiones a lo largo de su extensa producción lírica.

\footnotetext{
${ }^{24}$ Alonso, Dámaso: "Ligereza y gravedad...", cit., p. 59.

${ }^{25}$ Domínguez Caparrós, José: "Sonetos tridecasílabos...”, cit., pp. 1934-1935

${ }^{26}$ Jauralde, Pablo: “Tridecasílabos”. Rhythmica. Revista Española de Métrica Comparada, 2003, I, 1, pp. 125-147, p. 125.
} 
Tal vez no quedó satisfecho con sus resultados o quizás se encontrara más cómodo en el empleo de otros versos de ritmo endecasilábico y este uso circunstancial de los alejandrinos en el soneto tan sólo se tratara de un rasgo más de su evolución lírica que, con el paso de los años, iría tomando nuevos derroteros hasta acabar por aproximarse cada vez más a la poesía de raíz popular y al verso octosílabo.

Pero, por encima de todo, lo más destacado de este libro vendría a ser finalmente que don Miguel escogió la estrofa clásica del soneto como modelo de meditación lírica y que ya no dejaría de cultivarla hasta su muerte. "Se continuará" se titula el último poema de este libro y un soneto serviría también para cerrar su póstumo Cancionero.

Tras el Rosario de sonetos líricos, el ilustre rector salmantino empieza a desarrollar la que será su obra más granada, El Cristo de Velázquez, que verá la luz finalmente en el año 1920. El libro está estructurado en cuatro partes de diversa extensión, ${ }^{27}$ seguidas de una "Oración final", y son en total dos mil quinientos treinta y ocho endecasílabos libres o blancos los versos que lo componen. La obra es una especie de oratorio en la que Unamuno ofrece su particular visión de la figura de Cristo, tomando como modelo la representación velazqueña, y en la que son constantes las alusiones y glosas a los textos bíblicos que más le obsesionaron. ${ }^{28}$

La intención de Unamuno con este libro es asentarse sin discusión como poeta en el panorama de la lírica en lengua española en las dos orillas del Atlántico. Y para ello, seguro de sus posibilidades y con su habitual carácter de provocador, escogerá un nuevo modelo métrico ajeno a la moda del momento: una inmensa tirada de endecasílabos sin rima, pero que conviene a la perfección con el tono y el tema que trata. Así lo reconocerá en carta a Jiménez Ilundáin, fechada el 6 de noviembre de 1913:29

\footnotetext{
${ }^{27}$ Estas partes, a modo de cantos u oraciones, no llevan título alguno y se componen de treinta y nueve, catorce, veintisiete y ocho poemas respectivamente.

28 "A mí me ha dado ahora por formular la fe de mi pueblo, su cristología realista, y... lo estoy haciendo en verso. Es un poema que se titulará Ante el Cristo de Velázquez, y del que llevo escrito más de setecientos endecasílabos. Quiero hacer una cosa cristiana, bíblica y española. Veremos" (Carta al poeta portugués Teixeira de Pascoaes, 28 de julio de 1913) apud García Blanco, Manuel: “Introducción”..., cit., p. 24.

${ }^{29}$ Ibid.
} 
En Suramérica se respeta mi nombre; pero a los literatos les desconcierto un poco. Y sobre todo me regatean lo que yo más tomo a pechos: lo de poeta.

Aquí en España, empieza eso a cambiar. Y es que por allá están dominados por ridículos tecnicismos de rítmica y no saben leer. La verdadera poesía se les escapa. Puede usted, pues, decirles, para escandalizarlos, que preparo la publicación de un nuevo volumen de poesías y un largo poema en endecasílabos libres (llevo escritos más de mil) sobre El Cristo de Velázquez. Y me chiflo en las poesías requintadas y archiartificiosas de Lugones. Y desde luego que don José Zorrilla me hace daño a los oídos con el insoportable sonsonete de sus versos de tantán congolés.

La consideración religiosa del poemario concebido como un larguísimo salmo y la visión heroica de figura de Cristo, su carácter de concentración espiritual en quien emite el poema y a quien se dirige, hacen que el metro escogido con ausencia de rima sea el modelo formal perfecto. ${ }^{30}$ El propio Unamuno, y en ese mismo año de la declaración anteriormente citada (1913) en la que ha reconocido haber escrito varios centenares de versos, analiza los valores de este verso de la siguiente manera:

El endecasílabo libre o suelto es lo que más se acerca a la prosa ritmoide y ello obliga a cuidar la expresión poética, sin fiarse de los efectos técnicos de la versificación, casi siempre convencionales. Es la forma más libre, y a la vez, la más rica, porque el endecasílabo es el verso que más variedad consiente. ${ }^{31}$

El poeta vasco deja, pues, fluir sus versos con la misma serenidad y precisión que el pintor sevillano empleó para trazar su Cristo crucificado. Si Velázquez eliminó todo paisaje del fondo del cuadro para evitar cualquier distracción del espectador

${ }^{30}$ Como señala Domínguez Caparrós en su Diccionario de métrica española al tratar del verso suelto: "Por carecer de rima, se consideró un verso de tipo más cercano al verso latino y por eso se emplea en traducciones y es aconsejado para asuntos heroicos de amplio desarrollo. Porque el verso sin rima renuncia a uno de los elementos rítmicos, se hace necesario que esté más trabajado, notándose enseguida todo prosaísmo. De ahí que se tuviera por más difícil que el verso en el que hay rima". Domínguez Caparrós, José: Diccionario de métrica española, Madrid: Alianza, 1999, p. 487.

${ }^{31}$ Del "Prólogo" que escribe para la versión castellana del drama poético Constanza, obra del poeta portugués Eugenio de Castro. Unamuno, Miguel de: Obras completas, tomo VIII, cit., p. 1017. 
orante, sacrificando su maestría; Unamuno, fiel seguidor también en esto de su modelo, apartó también la rima para dejar sólo la fuerza del endecasílabo como preciso sostén de sus ideas, sin eco que distraiga a los lectores:

AMOR de Ti nos quema, blanco cuerpo; amor que es hambre, amor de las entrañas; hambre de la palabra creadora que se hizo carne; fiero amor de vida que no se sacia con abrazos, besos, ni con enlace conyugal alguno.

Sólo comerte nos apaga el ansia, pan de inmortalidad, carne divina. nuestro amor entrañado, Armor hecho hambre, ¡oh, Cordero de Dios!, manjar te quiere; quiere saber sabor de tus redaños, comer tu corazón, y que su pulpa como maná celeste se derrita sobre el ardor de nuestra seca lengua. ${ }^{32}$

Dos años más tarde, en 1922, Unamuno va a publicar un libro que es testimonio de la impresión que le provocan distintos lugares españoles que ha visitado entre 1911 y $1920 .{ }^{33}$ Este libro, cuyo título será Andanzas y visiones españolas, no es propiamente un poemario, aunque recoge, junto a los relatos de sus excursiones, una serie de poesías que agrupa bajo el rótulo de "Visiones rítmicas" y a las que habría que añadir cuatro sonetos del capítulo dedicado a la Granja de Moreruela. Lo más interesante, para el propósito de este trabajo, figura en el prólogo que antecede a esas ocho visiones rítmicas. Allí Unamuno justifica la inclusión de esas composiciones en verso como una necesidad provocada por una especie de armonía espiritual ante la contemplación de aquellos lugares y que, por esa misma razón, exigen cada una su propio ritmo de acuerdo con el referente. No se trata, sin embargo, de una musicalidad meliflua o de inspiración bucólica ante el paisaje, sino, como él mismo declara: "De una

\footnotetext{
$\overline{32}$ Unamuno, Miguel de: Obras Completas, t. VI. cit., p. 444.

${ }^{33}$ De hecho, los textos que componen la obra habían sido ya publicados con anterioridad mediante sus habituales colaboraciones periodísticas tanto en el diario bonaerense La Nación como en el madrileño El Imparcial. Cfr. García Blanco, Manuel: "Introducción"..., cit., p. 26.
} 
música, si acaso la tienen, esquinuda y rígida, angulosa y dura. Pero no todo ritmo se desenvuelve en curvas." 34 Y es que esa música peculiar que acaba de definir en los términos anteriores y que, en otro caso, podría entenderse como un desacierto, se justifica por su búsqueda constante de un ritmo que huya de lo cantable y bailable. ${ }^{35}$ Así, en esa cruzada a favor de una musicalidad propia, Unamuno ensayará aquí, como también haría Juan Ramón en algunas de sus obras, una disposición formal similar a la de la prosa en tres de estos poemas -"Los estrados de Albia", "Galicia" y "Junto a la vieja Colegiata"-, es decir, sin utilizar un renglón para cada verso. ${ }^{36}$

Desde el punto de vista métrico, Unamuno se sirve de la combinación clásica de la silva de endecasílabos, heptasílabos y pentasílabos blancos ("Los estrados de Albia") o con rima consonante ("En Gredos"), bien se vale de la silva arromanzada ("Galicia", "En un cementerio de lugar castellano", "El Cristo Yacente de Santa Clara"), o bien los agrupa en una forma estrófica de cinco versos blancos con la siguiente estructura: 11-,11-,11-,7-,5- (“Al Nervión”). En otros dos casos, también con ausencia de rima, recurre a una combinación diferente: la de decasílabos, tetrasílabos y hexasílabos ("Junto a la vieja Colegiata").

El siguiente poemario que lleve la firma de don Miguel verá la luz en 1923 con el título de Rimas de dentro. ${ }^{37}$ Sin embargo, la obra no va a aportar ninguna novedad a su producción pues, en puridad, sólo se trata de una breve recopilación de una veintena de poemas - escritos entre febrero de 1908 y junio de 1910- y

${ }^{34}$ Unamuno, Miguel de: Obras Completas, t. VI. cit., p. 499.

${ }^{35}$ Ibid., p. 500.

36 "Respecto a la forma externa o tipográfica de estos escritos he respetado en algunos de ellos la que al publicarlos por primera vez les di, y es ponerlos como si fueran prosa, sin hacer un renglón aparte de cada verso. Lo que por un lado obliga al lector a estar más alerta en su lectura y no dejarse guiar del artificio tipográfico -que a las veces simula versos donde no los hay-" (Ibid.). No obstante, ni el editor de sus Obras completas, Manuel García Blanco, ni Ana Suárez Miramón en la edición de Poesía completa, respetan el designio de Unamuno y reproducen estos poemas según la forma habitual en la disposición del verso.

${ }^{37} \mathrm{Su}$ difusión estuvo muy limitada, ya que se trató de una edición no venal y de breve tirada promovida por José María de Cossío quien dirigía en Valladolid una colección privada de poesía (Cfr. García Blanco, Manuel: "Introducción”..., cit., pp. 26-27). 
que, en su mayoría, permanecían aún inéditos. En cuanto a los procedimientos métricos que emplea el poeta bilbaíno destaca su insistencia en la combinación de endecasílabos, heptasílabos y pentasílabos, así como que la mayor parte de estos poemas carece de rima, aunque, en ocasiones, utilice el modelo de la silva arromanzada y sólo, por excepción, acuda al consonante.

No será, pues, hasta 1924, cuatro años después de la publicación de El Cristo de Velázquez, cuando Unamuno nos ofrezca un nuevo libro de versos auténticamente original: Teresa. Rimas de un poeta desconocido presentadas y presentado por Miguel de Unamuno. Curiosamente, el rector salmantino va a procurarse aquí una máscara literaria, en línea también con lo que hicieron otros contemporáneos suyos como Antonio Machado o el portugués Pessoa y, así, establece un cierto distanciamiento entre el autor de carne y hueso, cuya vida se transparenta biográficamente en tantas de sus composiciones, y un tal Rafael -Rafael de Teresa- al que atribuye la paternidad de los poemas que allí se presentan. Don Miguel se esconde, pues, en el papel de editor y confidente de ese apócrifo poeta, aunque la personalidad del escritor vasco es tan fuerte que no se resiste a desaparecer sin más y enmarca ese casi centenar de composiciones con su firma mediante una "Presentación" inicial y unas "Notas" finales, a las que seguirá, además, una explícita "Despedida". En ésta, expondrá lo siguiente:

Al escribir las notas de este libro manifesté que acaso no debí haberlas escrito, así como tampoco la Presentación que le precede, dejando que las Rimas, en su desnudez, dijeran por sí cuanto tienen que decir. Pero ahora, según voy viendo mi obra, me doy cuenta de todo el valor de este enmarcamiento de Teresa.

¡El valor de un marco! El marco, a la vez que aísla al cuadro del ámbito de la grosera realidad que suele cercarle, suele relacionarle con él. El marco representa una ventana abierta al infinito del arte, a la eternidad. ${ }^{38}$

En su larga presentación, Unamuno, aprovecha para indicar que la principal diferencia entre su poesía y la de este Rafael que le ha entregado sus versos es principalmente de carácter formal y prepara al lector poco avisado para que las observe. De este

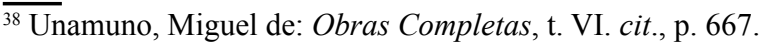


modo, señala que las teorías del apócrifo se inclinan por tesis más tradicionales que las suyas y así, por ejemplo, frente a su preferencia por lo que él llama el verso libre, esto es, carente de rima, Rafael siempre mantiene ésta y, sobre todo, del tipo consonante. ${ }^{39}$ Por ello, Unamuno no olvida apuntar a la "Epístola" que a él le dirige Rafael, donde, como justificación de su poética, se lee:

Que lo eterno es la vuelta, la carrera es el ritmo y la estrofa, y es la rima la pasada y futura primavera, las aguas que del mar quedan encima; es la canción eterna de la historia y el paso fiel que la quietud anima. ${ }^{40}$

Lo que resulta evidente por las declaraciones que aparecen en este libro es que la rima va a ir cobrando, cada vez más, una mejor valoración en la poética unamuniana. De lastre del poema va a pasar a elemento generador del mismo, de modo que la rima no sólo asocia los significantes de las palabras colocadas para tal efecto, sino que éstas quedan unidas también en cuanto a su significado, sugiriendo nuevos valores simbólicos; de modo que, el auténtico poeta se sirve de la rima para ir construyendo el poema y no como mera versificación de conceptos previos. ${ }^{41}$

En este nuevo ejercicio poético en el que el poeta parece reivindicar su condición de poeta enfrentándose a la vez a la tradición-Bécquer y la preceptiva clasicista están muy presentes en el libro-, a su propia obra anterior y, no lo olvidemos, a la poesía que por aquellos años harían los jóvenes del 27, Unamuno utilizará una enorme variedad de metros que atestigüen su dominio de los procedimientos métricos. En primer lugar, demostrará su versatilidad en el uso de muy distintos tipos de versos, desde el endecasílabo como verso rey -en solitario o en combinación con pentasílabos y heptasílabos- hasta el alejandrino, pasando por el tetrasílabo, el hexasílabo y el octosílabo; incluso algunos tan poco frecuentes en el conjunto de su obra por su ritmo y

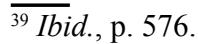

${ }^{40}$ Ibid., p. 647.

${ }^{41}$ Ibid., pp. 576-577.
} 
sonoridad tan marcados como los tridecasílabos dactílicos ( $3^{\mathrm{a}}$, $\left.6^{\mathrm{a}}, 9^{\mathrm{a}}, 12^{\mathrm{a}}\right)$, los dodecasílabos simétricos o dactílicos $\left(2^{\mathrm{a}}\right.$ y $5^{\mathrm{a}}$ de ambos hemistiquios), y los decasílabos anapésticos $\left(3^{\mathrm{a}}, 6^{\mathrm{a}}, 9^{\mathrm{a}}\right)$.

La misma variedad se aprecia en el uso que hace de las estrofas. En el amplio libro se encuentran, entre otras, pareados, tercetos encadenados, cuartetas, serventesios, quintillas, quintetos, octavillas agudas, un soneto o un romancillo hexasílabo que dan idea de ese ejercicio métrico al que el poeta se somete, tal vez, como apuntamos, para demostrarles a quienes aún dudaran de su capacidad como poeta -algo que siempre le obsesionó- su conocimiento de la tradición métrica y su capacidad creadora.

$\mathrm{Al}$ año siguiente de la publicación de Teresa, se va a producir un cambio de rumbo en su poesía. La conciencia civil y regeneradora a la que don Miguel no podía renunciar en ningún caso hacía de él un personaje polémico y molesto para las autoridades. $\mathrm{Su}$ enfrentamiento al poder político y al régimen monárquico haría que, en febrero de 1924, Unamuno fuese desterrado por el general Primo de Rivera. Pero el rector salmantino, como El Cid en la jura de Santa Gadea, va a superar con mucho el límite temporal del destierro señalado por el dictador y, aunque éste levanta la pena a principios de julio del mismo año, don Miguel marcha desde las Islas Canarias a París, y más tarde a Hendaya, para no regresar a España hasta la caída del general en 1930.

De estas circunstancias vitales procede su De Fuerteventura a París. Diario íntimo de confinamiento y destierro vertido en sonetos, publicado en la capital francesa en 1925. El libro se articula en dos partes, coincidentes la primera con el periodo que va desde su salida de Salamanca hasta su viaje en barco camino de Francia (sesenta y seis sonetos del total) y la segunda con su estancia en París en el periodo comprendido entre septiembre y diciembre de 1924 (treinta y siete sonetos). Más allá de la evidente presencia de los temas de carácter político y de queja por la pasividad social de muchos españoles -aunque también los hay de carácter religioso y hasta paisajísticos-, interesa destacar aquí esa insistencia en un mismo molde estrófico para el conjunto del poemario y su preferencia por el orden cronológico como eje vertebrador de la obra, exigido en este caso por ese valor de diario que se subraya en el subtítulo. 
Esta insistencia en el soneto no parece totalmente similar a la que pudo aparecer en su Rosario de sonetos líricos (1911) como señal de dominio en la clásica estrofa, sino más bien consecuencia de aplicarse a sí mismo el criterio de Castello Branco cuando éste afirmó que "el soneto es un gran respiradero de pasiones, una óptima sangría para evitar congestiones cerebrales" y que tanto parece haber influido en el caso del ilustre bilbaíno. De esta forma, tal vez, Unamuno se habría servido de tan prestigiada fórmula métrica para transmutar ese dolor agónico del desterrado en una colección de poemas precisos en su diseño diamantino y con los que conculcar la desesperación de quien se ve privado de su tierra y sus seres queridos. Así, pareció verlo el mismo don Miguel cuando, al inicio de la obra, se pronuncia sobre el valor de esta estrofa como un reto artístico que provoca al poeta y que, una vez conseguido, produce una especial satisfacción a su creador: "iqué intensidad de emoción no alcanza un sentimiento cuando se logra encerrarlo en un cuadro rígido, en una forma fija, cuando se consigue hacer un diamante de palabras con sus catorce facetas lisas y brillantes y sus cortantes aristas!" ${ }^{43}$

Y, más adelante, en otro lugar del libro, el desterrado de Salamanca invoca su derecho a utilizar el soneto con una nueva misión más allá del carácter reflexivo y amoroso que le había asignado la tradición literaria al uso de esta estrofa. La poesía, que es también un arma, puede blandirse amenazadoramente contra los enemigos, incluido el prestigioso soneto. Con su habitual entusiasmo, Unamuno reivindicará esta postura al afirmar: "Y yo añado que cabe pelear a guitarrazo limpio. $\mathrm{O}$ a sonetazos". ${ }^{44}$ Por lo demás, pocas innovaciones pueden señalarse en su uso, salvo el original empleo que hace del endecasílabo de gaita gallega en el soneto XLVIII, donde aparece sistemáticamente y con la peculiaridad de que el último de sus versos exige un desplazamiento acentual hacia la séptima sílaba. Si su empleo en la

\footnotetext{
$\overline{42}$ Texto que Unamuno había citado en su "Presentación" a Teresa reproduciendo las palabras del autor portugués en la que, con evidente ironía, se refería al uso de la estrofa en poesía y, especialmente, en lo relativo a la literatura amorosa. (Ibid., p. 570).

${ }^{43}$ Ibid., p. 674.

${ }^{44}$ Ibid., p. 714.
} 
métrica española resulta llamativo por escaso, resulta aún más extraño en el caso de Unamuno a quien tan poco contentaban esos ritmos demasiado repetitivos y sonoros.

Cuando en julio de 1927 prepara en Hendaya el prólogo del que habría de ser el último poemario que vería editado, Romancero del destierro (1928), don Miguel plantea la obra, en cierto modo, como una continuidad del libro anterior. En primer lugar, mantiene su condición de exiliado, si bien ya no pesa sobre él orden judicial alguna, y, en segundo lugar, aunque no menos importante, está la reivindicación que hace de una poesía política o, mejor, ligada directamente a las circunstancias del presente. Por ello, y sabiendo que conviene prever los ataques, clamará desde

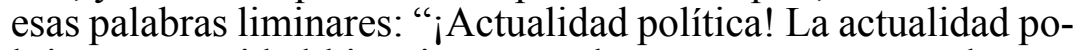
lítica es eternidad histórica y, por lo tanto, poesía. Y nada más actual que lo circunstancial cuando se le siente en eternidad". ${ }^{45}$

En el mismo texto aclara que, con exactitud, sólo cabría titular así a la segunda parte el libro, formada por dieciocho romances, ya que la primera está conformada treinta y siete poesías de variado metro y rima. Y así, desde el punto de vista métrico, la primera parte no presente novedades destacables. Predomina el uso del ritmo endecasilábico en las formas que el poeta acostumbra, bien con uso exclusivo del endecasílabo en algunos poemas, bien alternando aquél con heptasílabos y pentasílabos; además de utilizar también en otros poemas versos hexasílabos, octosílabos, eneasílabos o decasílabos. En el plano estrófico, además de sus habituales composiciones polimétricas y los ineludibles sonetos, aparecen cuartetas, serventesios, sextetos; aunque también hace algunas variaciones como la de utilizar la estructura del romance pero agrupando los versos de cuatro en cuatro, siendo el último de cada grupo de pie quebrado, o bien crea un ritmo de canción infantil alternando octosílabos y tetrasílabos de manera casi continuada y con rima asonante en los pares:

¡Habla, que lo quiere el niño! ¡Ya está hablando!

$\overline{{ }^{45} \text { Ibid., p. } 741 .}$ 
El Hijo del Hombre, el Verbo encarnado,

se hizo Dios en una cuna

con el canto

de la niñez campesina, canto alado... ${ }^{46}$

En la segunda parte del libro, como se indicó, sólo figuran romances y en éstos apenas uno, el señalado con el número XI, ofrece una variación digna de destacarse: la presencia, a partir del verso sexto, de la palabra Salamanca -título de toda la composición- y que como tetrasílabo se irá repitiendo cada tres octosílabos a manera de leitmotiv. Pero, sin duda, lo más interesante de esta sección es, a nuestro juicio, que abre una puerta en la poética unamuniana por la que esta estrofa, no demasiado utilizada por el autor hasta entonces y que entronca con las raíces primigenias de la métrica española, va a proyectarse en gran parte de su última producción y donde el octosílabo pasará a convertirse en el verso rey.

Unamuno no descansará de escribir poesía hasta estar a las puertas de la muerte. Más aun, incrementa su actividad poética en detrimento de su dedicación literaria a otros géneros, con excepción de sus numerosos artículos periodísticos. Toda esta ingente creación lírica -desde febrero de 1928 hasta diciembre de 1936- irá a parar a su póstumo Cancionero, que no vería la luz hasta 1953. Allí, las 1755 composiciones, organizadas de nuevo cronológicamente, como era su deseo ${ }^{47}$ trazan un panorama literario y vital del poeta vasco, además de resultar fundamentales para conocer innumerables aspectos de su postrera visión sobre la lírica.

Resalta en su Cancionero esa defensa apasionada de una poesía impura, abonada por la realidad más inmediata y que se

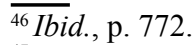

${ }^{47}$ En el prólogo para una proyectada edición de la obra, Unamuno afirma: "Las canciones van publicadas [...] por el orden temporal de su nacimiento, que es el orden más vivo pues han nacido unas de otras. El desorden, el caos o bostezo, sería enfilarlas por géneros, por temas, por metros o por tonillos. El orden más práctico suele ser el más artificioso: el alfabético. Entre todos ellos forman, creo, un poema de gran unidad, de la estrecha e íntima unidad que da la vida. Y son, me atrevo a afirmarlo, poesía y filosofía, si es que éstas se diferencian entre sí” (Ibid., p. 941). 
aleja a conciencia de las modas poéticas del momento, su gusto por el lenguaje popular ligado a la tradición y el poder creativo de la palabra en el que atiende tanto a su aspecto formal como al conceptual. ${ }^{48} \mathrm{Su}$ afán de perdurabilidad lo cifra, cada vez más, en esa pervivencia de su poesía, de manera que a la vez que la hace se hace a sí mismo y todo en torno a esa conciencia del ser para la eternidad que don Miguel reivindica. Por eso, su poesía no admite selecciones del conjunto total y porque supondría, además, una falsificación de ese Diario poético que plantea el subtítulo. ${ }^{49}$

En cuanto a los aspectos métricos, su Cancionero destaca, principalmente, por la brevedad de sus composiciones. Así, si examinamos los cuadros de versificación presentados por el profesor De Kock, ${ }^{50}$ se computan un total de 557 poemas de cuatro versos, seguidos en frecuencia por aquellos que tienen ocho y doce versos, con 294 y 265 poemas respectivamente. Junto a éstos, existen poemas aún más breves, 15 de dos versos y 8 de tres, y sólo 116 superan los dieciséis versos. Su estructura

$\overline{48 \text { "C }}$ reo tener que decir que el lenguaje mismo, el lenguaje popular, ha sido un inspirador capital. Las palabras mismas suscitan ideas [...]. Los llamados aciertos poéticos suelen ser aciertos verbales. Hay tal juego de palabras que es juego de conceptos, conceptismo y juego de pasión. Porque las palabras levantan pasiones y emociones; y acciones" (Ibid., p. 942). Y, más adelante, vuelve a insistir: "Y lo que crea es la palabra y no la idea. Y así, he logrado hacer un diario espiritual, no ideal. Que si la idea es idea, la palabra es espíritu. Y el espíritu es santo -Espíritu Santo- y es divino, como el Verbo. Lo que no es la Idea, la Visión, la palabra ideal, visiva, no es más que un vestido, a las veces espléndido y maravilloso de hermosura; la palabra espiritual, poética, es carne de pensamiento que se siente y se vive. Y es una palabra que piensa, sueña, crea por sí misma” (Ibid., p. 948).

${ }^{49}$ En ese mismo prólogo, escrito en noviembre de 1928 y que funciona de manifiesto poético de su última producción, afirma como colofón: "Y parece como si este retoñar de canciones -casi cada día me trae la suya, siquiera una sentencia fugitiva- fuese que mi alma quiere vaciarse de todo lo que tiene que decir antes de entrar en el eterno silencio del reposo. Pero ¿por qué no las cierno y selecciono y dejo las unas para no publicar luego sino las otras? ¿Y cuáles sí y cuáles otras no? Todas, buenas y malas, mejores y peores. Todas, sí, pues son miembros de un solo cuerpo al que no me cabe cercenar ni mochar; todas. Las buenas abonarán a las malas y las malas no malearán a las buenas. Unas y otras, y todas, se completarán y conllevarán. La poda puede hacer un jardín urbano, pero deshace un bosque montañés. Lo mejor que puede haber aquí necesita, para su mejor disfrute, de lo peor que se haya deslizado. Con los deshechos se abona -esto es: se hace bueno- lo escogido. Quede, pues, todo" (Ibid.).

${ }^{50}$ Kock, Josse de: Introducción al Cancionero de Miguel de Unamuno. Madrid: Gredos, 1968, pp. 110-113. 
métrica suele ser bastante simple y se basa en breves agrupaciones de cuatro o tres versos, siendo los esquemas más empleados los del tipo $a b a b$ (634 poemas), abba (276), $a a b c c b$ (76). Esta brevedad afecta al plano sintáctico, de manera que cada una de estas pequeñas estrofas recoge una sola frase que singulariza también el concepto que en ellas se vierte.

El octosílabo es el metro predominante en el poemario, pues figura en 974 composiciones del total; si bien el número es susceptible de ser ampliado hasta 1040, sumado a la primera cifra otros poemas en los que el octosílabo se combina con el tetrasílabo. Culmina así esa tendencia que se había iniciado en su Romancero del destierro y que de nuevo lo aproxima a la poesía tradicional castellana y a los ritmos de la canción popular. Por el contrario, el metro hasta entonces preferido, el endecasílabo, empleado en exclusiva o en combinación con versos de nueve, siete o cinco sílabas, sólo aparece en 200 de estas canciones. La razón de esta inversión en su preferencia puede deberse, como señala Josse de Kock, ${ }^{51}$ a la sustitución del concepto de ritmo por la idea de compás. Esto es, a la predilección tantas veces enunciada desde los inicios de su obra por los ritmos matizados y suaves -que tomaba como referencia el ritmo endecasilábico $\mathrm{y}$, en muchas ocasiones, la ausencia de rima- sucede ahora la primacía que otorga a ritmos mucho más marcados, entre los que el octosílabo le ofrece una nueva gama de posibilidades.

Del mismo modo, esa evolución se hace patente en su consideración de la rima. ${ }^{52}$ Tras sus inicios en los que llegó a abominar de ella o a soportarla como un lastre del que no podía desprenderse y a sus indicaciones en defensa de una poesía sin rima como medio de que el lector no sufriera distracciones innecesarias, ahora sólo 46 poemas de los 1755 que componen su Cancionero carecen de este elemento, mientras que 1363 de sus canciones optan por seguir el consonante y 350 -situados fundamentalmente al inicio del Diario- riman en asonancia. Esta tendencia hacia la rima consonante que ya había explorado en profundidad en sus sonetos, aunque entonces fuera por exigencia métrica de la estrofa, puede interpretarse ahora como un proceso

$\overline{{ }^{51} \text { Ibid, pp. } 86-89 .}$

${ }^{5}$ Ibid., p. 113. 
de densidad conceptual que se apoya en este procedimiento métrico. ${ }^{53}$ Ahora, la rima se convierte en elemento estructural de la obra y se proyecta más allá del plano fónico, consiguiendo establecer relaciones que provocan imágenes insospechadas y que, a su vez, enlazan con otros efectos iterativos del verso desde el paralelismo, la anáfora o la anadiplosis a los innumerables juegos etimológicos que establece.

En conclusión, la poesía de Unamuno se muestra rica en todos sus aspectos formales y de contenido. En este sentido, los aspectos métricos -el uso del verso, la aceptación de los modelos estróficos o la libre creación de éstos según sus necesidades, así como la consideración del papel que juega la rima en el poemasuscitan en don Miguel una preocupación continuada hasta su muerte. Y si su vida fue un constante hacerse al margen de las doctrinas dominantes, del mismo modo diseñó una poética propia que, en muchos casos, funciona a contracorriente. Estas consideraciones deben ser tenidas en cuenta al valorar su poesía, al mismo tiempo que debe huirse de estereotipos ajenos a la creación lírica y que, en no pocos casos, han pretendido reducir la poesía de este autor singular a una especie de filosofía rimada. Unamuno es un poeta, nada menos que todo un poeta.

\footnotetext{
$\overline{{ }^{53} \text { Ya }}$ en sus palabras de "Presentación" a Teresa (1924) había hecho notar este proceso: "Las primeras rimas de mi Rafael de Teresa están, sin duda, influidas por las de Bécquer, flojo versificador, y están, como las de éste, no más que asonantadas, artificio del que apenas nos servimos ya más que los españoles. Pero se ve luego que, a medida que adensa su pensamiento poético, acude al consonante" (Unamuno, Miguel de: Obras Completas, t. VI. cit., p. 577).
} 